\title{
Importance of automobile interior for sustainability in the automotive industry: The case of volume manufac- turers
}

\author{
Wanja Wellbrock ${ }^{1 *}$, Daniela Ludin ${ }^{2}$, Linda Rohrle ${ }^{3}$ \\ 1,2,3 Faculty for Management and Sales, Heilbronn University of Applied Sciences, Heilbronn, Germany
}

\author{
Keywords \\ Sustainability \\ Automotive industry \\ Interior \\ Innovation
}

Received: 17 April 2018

Accepted: 22 May 2018

Published: 5 June 2018

\begin{abstract}
The contribution focuses exclusively on volume manufacturers because the spread of sustainability effects is more limited for this market segment than premium brands. An empirical study is used to determine the expectations on the customer side regarding more sustainability in the automotive industry in general and in the interior sector in particular and to derive corresponding challenges and potentials for original equipment manufacturers. The empirical study is based on an online survey with randomly selected persons via social media. The survey was conducted via Survey monkey. All persons with a minimum age of 18 years were considered. A majority of 63 percent of all volume brand customers are willing to pay a higher price for additional costs related to the use of natural and sustainable materials. All participants principally agree that sustainability should play an overall role in the automobile and should not be restricted to individual areas. Further research projects will analyze whether there are significant differences when it comes to premium manufacturers. Furthermore, no distinction has been made between age, gender, and automotive brand. All of these can be explored in the scope of further research activities, too.
\end{abstract}

(C) 2018 The Author(s). Published by TAF Publishing.

\section{SUSTAINABILITY AS A MAJOR CHALLENGE FOR THE AUTOMOTIVE INDUSTRY}

Sustainability is regarded as the keyword of the 21st century and the importance of the topic is not yet sufficiently widespread $[1,2]$. The associated topic of resource conservation, which has been important since the 18th century, is now more relevant than ever. Above all, the automotive industry, which is the most important branch of industry in terms of turnover and the growth engine for Germany, has to deal more intensively with sustainable development and the associated effects and challenges. Automotive manufacturers are under pressure to comply with both political guidelines and internal specifications, as well as with constantly changing individual customer wishes $[3,4,5]$.

For the automotive industry, topics such as electric motors and the associated optimization areas, lightweight construction and $\mathrm{CO}_{2}$ emission reduction are key issues. Never- theless, the car's interior cannot be ignored. After all, the interior is the part of a car most frequently seen by the driver and must therefore be practical, aesthetically pleasing and at the same time weight saving. The use of natural fibres as alternative materials in the interior plays an important role and is a further step towards greater sustainability [6, 7]. Consequently, the following research question arises: How do the three pillars of sustainability (economical, ecological and social issues) influence interior development at volume brand manufacturers and how do customers accept sustainable solutions? The contribution focuses exclusively on volume manufacturers, therefore premium manufacturers as Audi, BMW, Mercedes-Benz and Porsche are excluded. The spread of sustainability effects is more limited at this market segment compared to premium brands and can be seen as an existing research gap.

Based on a literature review on sustainability in the auto-

\footnotetext{
${ }^{*}$ Corresponding author: Wanja Wellbrock

†email: wanja.wellbrock@hs-heilbronn.de
} 
motive industry, previous efforts to increase sustainability in the interior sector will be presented. Subsequently, an empirical study is used to determine the expectations on the customer side regarding more sustainability in the automotive industry in general and in the interior sector in particular and to derive corresponding challenges and potentials for Original Equipment Manufacturers (OEM).

\section{SUSTAINABILITY IN THE AUTOMOTIVE INDUSTRY}

Long-term success in the automotive industry is connected to consistent innovation strategies, strong branding, global efficiency in the value chain and qualified and motivated employees. Innovation management can be stated as the key long-term success factor - after all, no other industry invests more than the automotive industry in this area. Currently, the automotive industry is witnessing the greatest phase of upheaval in its history. Mega trends such as emission reduction, lightweight construction, automated driving, connectivity and mobility services have changed the landscape for good. In line with these trends, the supplier industry is also adapting and undergoing fundamental changes $[8,9,6]$.

The topic of sustainability in the automotive industry is also gaining more momentum in the scientific community. Nunes and Bennett, for example, carry out a fundamental comparison of environmental initiatives of automobile manufacturers, conclude that these are often still very vague, and require further concretization. Another criticism is that the focus is primarily on the ecological dimension [10]. [11] develop a theoretical framework for analysing the influence of green and lean SCM practices on the sustainable development of automobile manufacturers. Ecological (e.g., $\mathrm{CO}_{2}$ emissions), social (e.g., supplier screening) and economic (e.g., operating costs) aspects are considered as performance indicators [11, 12]. [13] complement this with an analysis of a sustainable business model for the automotive industry that integrates all three dimensions of sustainability. This paper also shows that there has been a clear improvement in sustainability performance in the automotive supply chain over the last decade [13]. [14] emphasize that sustainability management in the automotive industry is only possible through a holistic process approach starting with the conception and continuing right up to the series production of the product. In addition to these rather conceptual contributions, several authors consider concrete materials about their sustainability potential for the automotive industry [14]. [15] consider, for example, the suitability of bio composites especially in the field of dashboards [15], whereas [16] focus primarily on the suit- ability of natural fibres [16]. [17] consider the specific attitude of motorists towards sustainable materials in the interior sector. The focus here is on the willingness of customers to actually pay more for renewable raw materials [17].

Overall, the issue of sustainability in the automotive industry may well be gathering momentum and scientific focus, but the interior design sector in particular has been largely neglected. The article attempts to close this gap.

\section{SUSTAINABILITY IN THE AUTOMOTIVE INTERIOR}

The widespread innovation efforts in the field of electric mobility and autonomous driving also offer the potential to rethink and redesign the car's interior. The vehicle interior has to be transformed into an increasingly attractive living space. This can be achieved, for example, through attractive surfaces made of sustainable materials. The interior plays an increasingly important role in purchasing decisions. It arouses emotions, offers comfort, safety and functionality and radiates brand identity as a fusion [18].

The interior of a vehicle can be divided into six assemblies: the cockpit, the seats, the door and side trim, the headliner, the luggage compartment and the floor trim. Developments in this area are a balancing act between the pressure to innovate and the need to keep costs down [19].

\section{A. Characteristics of Natural Fibre Materials}

Already in 2005, more than 30,000 tons of natural fibres were used in the automotive industry in Europe [20]. In 2015 , the figure was already 50,000 tons, of which ten to 20 percent were European hemp fibres. Hemp belongs to the category of baste fibres, which are most frequently used in automotive components. Hemp, kenaf and flax are suitable alternatives to glass fibres because they are less expensive, have a lower density, a high strength and are more environmentally friendly. The use of natural fibres can result in cost savings of ten to 30 percent compared to glass fibres. Due to its strength, it can be used as a reinforcement for vehicle interior parts such as door panels. In addition, kenaf, which is cultivated mainly in China and Thailand, has one of the best $\mathrm{CO}_{2}$ absorption rates in the plant world $[16,20]$.

Another advantage is that the natural fibre-reinforced plastic does not splinter and can break without creating sharp edges. Its low weight and high load-bearing capacity are an advantage for lightweight construction and safety requirements and have a positive influence on crash management. Due to the positive cost performance ratio and the other advantages described, composite materials based on natural fibres have been used for several years for thermoplastics, 
thermosets and elastomers in automotive interiors. Wellknown examples of this are doors made of flax or sisal fibres and polymeric binders such as polypropylene (thermoplastic) or polyurethane $[21,18]$.

When selecting alternative materials, great care should be taken. For one, fibres from natural sources are not always more environmentally friendly than conventional fibres. Large amounts of water, pesticides, chemicals and energy are needed to prepare and dye the fabric during cotton degradation and processing. In addition, natural fibre reinforced plastics are neither as strong nor durable as metal or synthetic fibres, so they need to be replaced more frequently, resulting in increased energy consumption in the long term.

Whereas natural fibres were previously concealed behind a thick film lamination, they are now becoming more and more visually perceptible and are increasingly finding their way into the premium interior as a design element. At the same time, suppliers and vehicle manufacturers are in equal demand to conduct even more intensive research in the field of natural fibre-reinforced plastics and to bring technologies to series maturity that make it possible to further increase the proportion of natural fibres in vehicle interiors [16].

\section{B. Sustainability Measures in the Interior}

The new hybrid materials and vehicle concepts pose a challenge for manufacturers and suppliers. The lightweight construction required for this should continue to offer the best surfaces in the interior since the appearance conveys a direct impression of quality. Therefore, corresponding solutions with bio-composite materials are of great importance, as, for example, the supplier Draxlmaier shows with his Kenaf door trim for the BMW i3 electric vehicle. The component is made exclusively of natural fibre-reinforced polypropylene with functional elements [22, 23].

The use of natural fibre materials as a design element that underlines the sustainable character of a vehicle was not an option until now. They had not previously met the requirements of OEMs for a high-quality appearance and the technical process conditions of the manufacturers made it difficult to use the materials. After a long development period, the supplier Draxlmaier and the manufacturer BMW have now joined forces to bring the innovation of visible natural fibres in the interior to series maturity. Requirements for design elements and weight reduction have been met and, at the same time, the materials are ecologically compatible. The "Fast Fibre Forming" developed by Draxlmaier makes it possible to implement the "Visible Nature". Panels are made of kenaf fibres and coated with a wafer-thin transparent plastic film. The purity of the plant material used ensures a particularly high-quality surface appearance compared to other natural raw material sources such as hemp or flax [22].

In the BMW i3, the visible door beams and the instrument panel cover are also made of the fibres of the tropical mallow plant Kenaf. The reasons for the selection are that Kenaf has a high degree of fineness and purity of the fibres compared to flax and hemp, which is essential for a high-quality surface. This is an elementary prerequisite because the design philosophy of BMW i vehicles combines a consistent focus on sustainability, which becomes visible and tangible in the interior, with simultaneous fulfilment of the OEM's premium claim [24]. A further example is presented by Johnson Controls for the new BMW 3 Series with wood fibre components that not only relieve the burden on the environment, but also reduce weight by 20 percent compared to solutions previously used [25].

The use of renewable and natural raw materials as a sustainable alternative to plastics is in direct harmony with the needs of the young generation. Yanfeng Automotive Interiors, for example, deliberately presents the recyclable, artistically designed natural fibre middle parts of the door panel in a natural look. According to Han Hendriks, Chief Technology Officer at Yanfeng, there is currently a shift towards more personalisation and individualisation. Drivers want to be sustainable and at the same time be safe and in touch with the spirit of the times [26].

The supplier International Automotive Components (IAC) optimizes component designs for OEMs. A new product is the "Fibre Frame" technology. The natural fibre semifinished product "EcoMatHot" replaces the classic material sheet steel in the mounting frame of the vehicle roof lining with panoramic or sliding roofs. The material consists of 70 percent renewable raw materials. A weight reduction of up to 50 percent is possible [8].

In the future, it is expected that the use of renewable raw materials and recycled materials will continue to gain in importance. Visible components made of renewable materials will be found more frequently in the interior of the cars of tomorrow. In this context, the natural materials must be designed haptically and optically so that they can no longer appear only in laminated or mixed form with plastics [25]. 


\section{EMPIRICAL STUDY ON CUSTOMER EXPECTATIONS REGARDING SUSTAINABILITY ASPECTS IN AUTOMOTIVE INTERIOR}

An empirical large-volume study is conducted to investigate the expectations and potentials that customers see in sustainability elements, particularly in the interior sector. The empirical survey focuses exclusively on customers of volume brands (e.g., VW, Opel, Skoda, Renault, Ford, Toyota etc.). Premium brands as Audi, BWM, Mercedes-Benz or Porsche are excluded, since sustainability measures are already more widespread in this area and customers have even higher expectations with regard to design and equipment [27]. Especially the topic of volume brands can be marked as an existing research gap.

\section{A. Structure of the Empirical Study}

The empirical study is based on an online survey with randomly selected persons via social media. The selected persons are from the Heilbronn University of Applied Sciences, the University of Stuttgart and the company Valeo Schalter und Sensoren in Bietigheim-Bissingen. The survey was conducted via Survey monkey. All persons with a minimum age of 18 years were considered. A limitation to certain industries was not carried out. 254 participants fulfilled the desired characteristics - 69 percent male and 31 percent female. With regard to volume brands, Volkswagen dominates with 35 percent, Opel, Ford and Skoda follow with ten, nine and seven percent.

The questionnaire consists of 23 questions, divided into three sections: "general sustainability", "specific sustainability in the automotive industry and the interior" and "future expectations".

\section{B. Empirical Results}

The participants of the study recognize the fundamental importance of sustainability. For 72 percent nutrition is the area of life with the highest importance of sustainability, followed by energy supply (68 percent) and habitation (64 percent). Mobility follows on rank four with 52 percent (see Figure 1). This shows that a fundamental need for sustainability exists, but sustainable mobility is only important for half of all included customers.

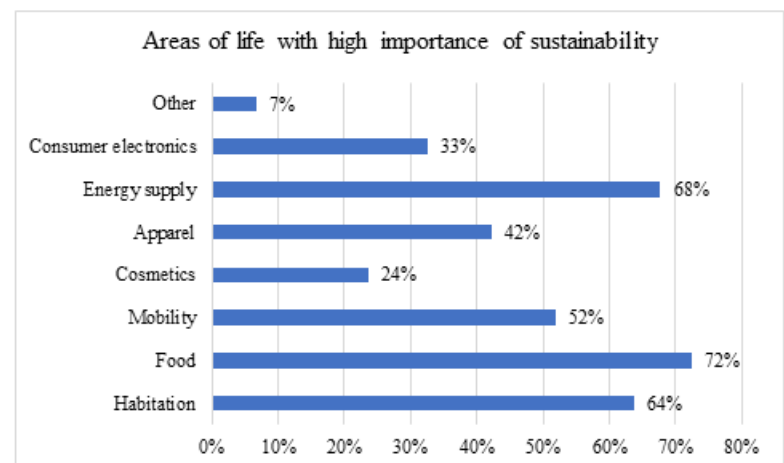

Fig. 1. Areas of life with high importance of sustainability ( $n$ $=254$ )

Looking at the factors decisive for buying a car, quality, price, performance and design are on the first ranks. Sustainability plays an relevant or even very relevant role for only 39 percent of the respondents, which is the second lowest value of all factors. Only brand achieves a lower percentage (see Figure 2). This shows that sustainability effects have only a limited influence on customers' purchasing decisions, the focus is still on traditional aspects as quality, performance, price and design.

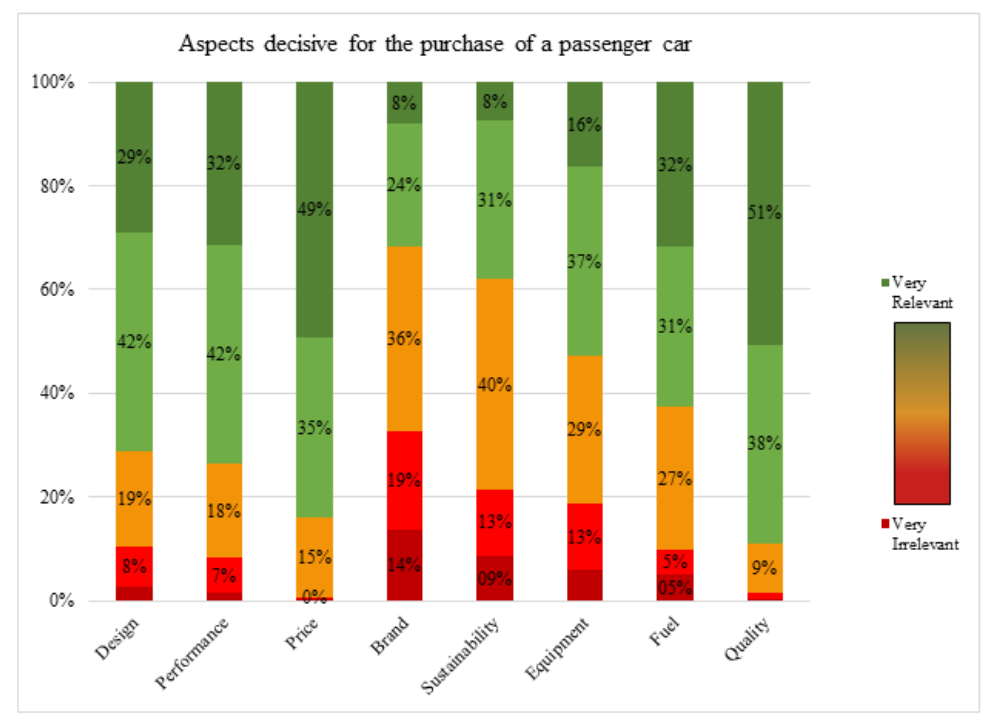

Fig. 2. Aspects decisive for the purchase of a passenger car $(n=254)$ 
The acceptance to pay for additional costs for sustainable materials in the car is present for 63 percent of all participants. Only 37 percent do not accept higher prices due to sustainability aspects in the car. Therefore, a basic willingness to accept higher costs exists among costumers of volume automotive brands.

Analysing single modules of an automobile, interior and electronics (both 70 percent) receive the highest relevance for sustainability from the customer's point of view. Power unit follows on rank three with 66 percent. Only 16 percent see no potential for sustainability in automobiles at all (see Figure 3). The result shows that interior is on the focus of customers regarding sustainability and manufacturers should pay more attention to this topic. The further questions now relate exclusively to the automotive interior.

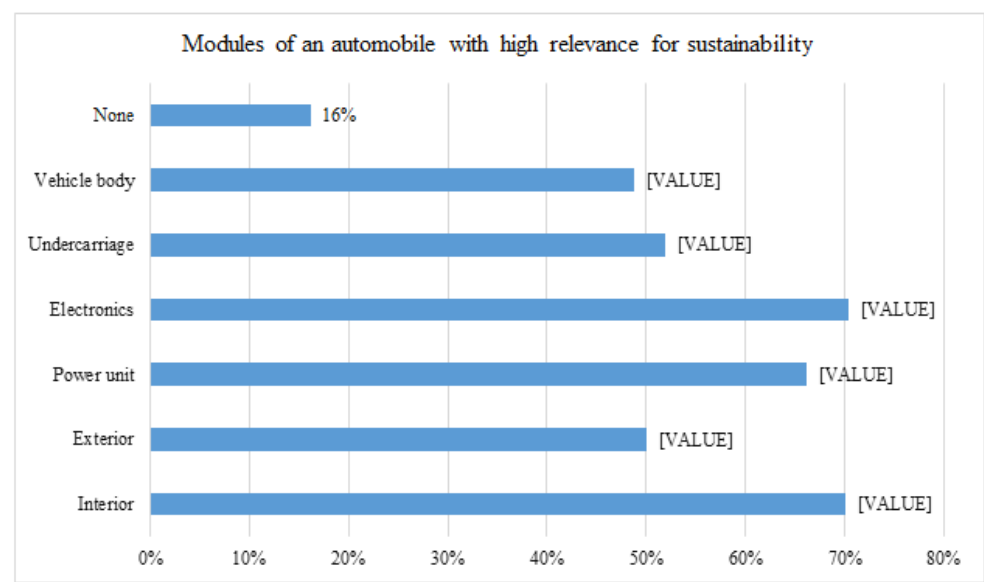

Fig. 3. Modules of an automobile with high relevance for sustainability $(n=$ 254)

A majority of 74 percent of all volume brand customers agree that the OEM should place more emphasis on the selection of sustainable and natural materials in the interior. Only six percent reject it, which represents a clear message to the OEM and emphasizes the message from Figure 3. In order to control the customers' design perception of natural materials in the interior, a picture of an untreated door panel was shown to the participants (see Figure 4). The reaction to whether the test persons could imagine this in their automobile was very positive. 76 percent of the respondents could imagine such a door, if properties as haptics, appearance and economy are retained. Only 15 percent of the respondents could not imagine such a door in a volume brand automobile.

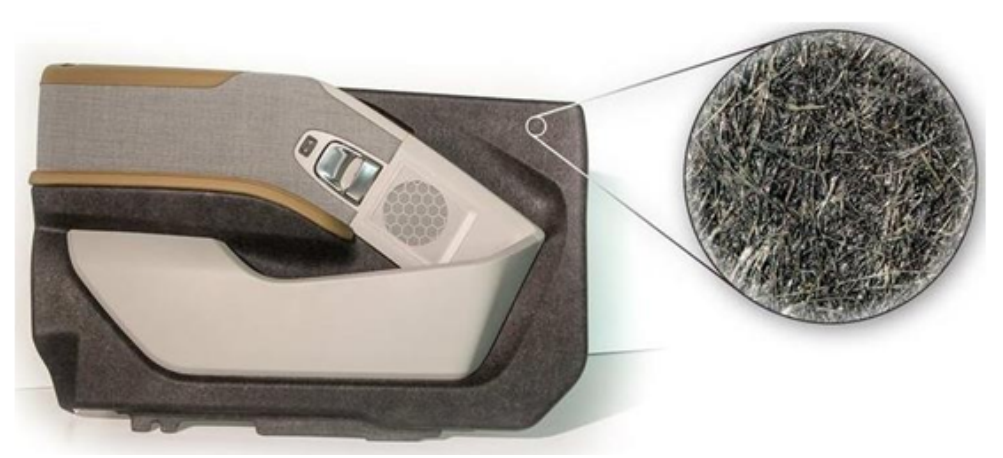

Fig. 4. Untreated door panel with natural materials (Source: Draxlmaier, 2018)

Looking at additional aspects, needed to be fulfilled by sustainable and natural materials in the interior, safety and quality (each 93 percent) receive the highest percentages based on the statuses "very important" or at least "impor- tant", followed by smell (82 percent), comfort (81 percent), optics (77 percent) and haptic ( 72 percent). The lowest percentage receive individuality with only 28 percent (see Figure 5). 


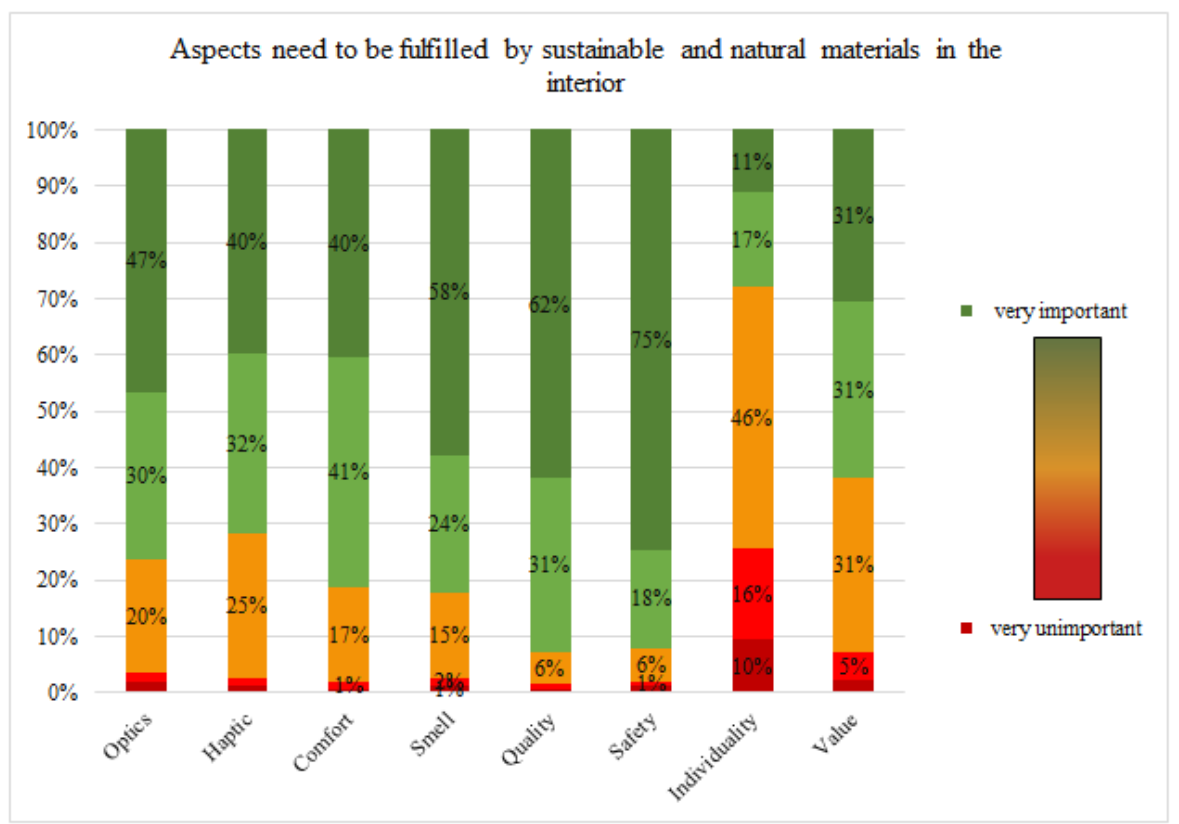

Fig. 5. Aspects need to be fulfilled by sustainable and natural materials in the interior $(n=$ 254)

Looking at individual types of material, volume brand customers would like to see more sustainable alternatives in the interior for plastics (70 percent), leather (55 percent), textiles (54 percent) and wood (45 percent) (see Figure 6). Especially for the first three materials, sustainable solutions are already available, as described in the previous chapter. Regarding the variety of natural alternative materials, recycled materials (58 percent) and biometic plastics (51 percent) receive the highest percentages of people evaluating it as relevant or even very relevant for the interior sector. Overall, all known alternative materials such as ligneous, hemp, kenaf or sisal are well accepted by customers and the percentages for irrelevance are far lower for all materials (see Figure 7).

As an optional question, the participants were asked to decide which material they prefer for which interior component. The blue marked words are the materials with the highest customer percentage (see Figure 8). The results show that the materials selected for the door panel, decorative elements, foot area, armrest and seat are already natural. Other natural materials such as recycled material or natural rubber also achieve a high level of approval for individual interior components, although they do not yet represent a majority opinion.

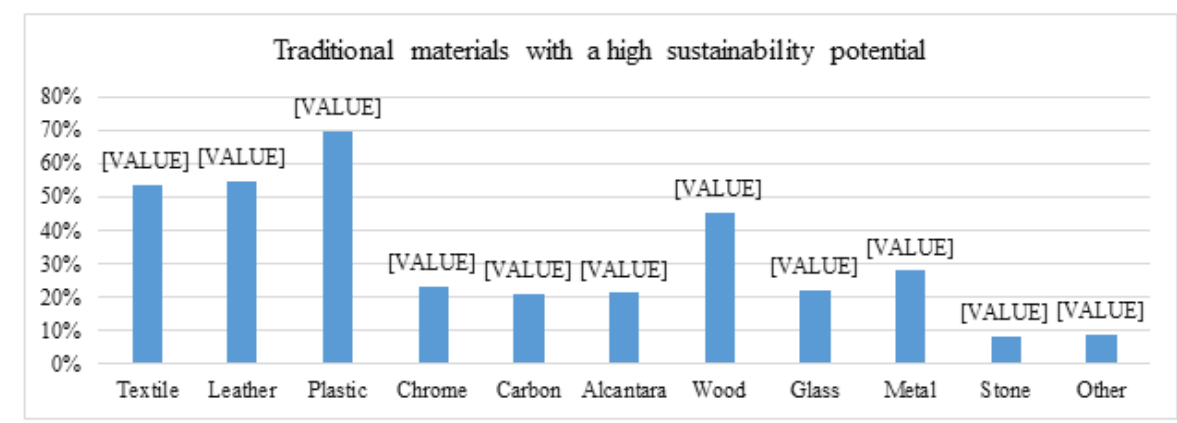

Fig. 6. Traditional materials with a high sustainability potential $(n=254)$ 


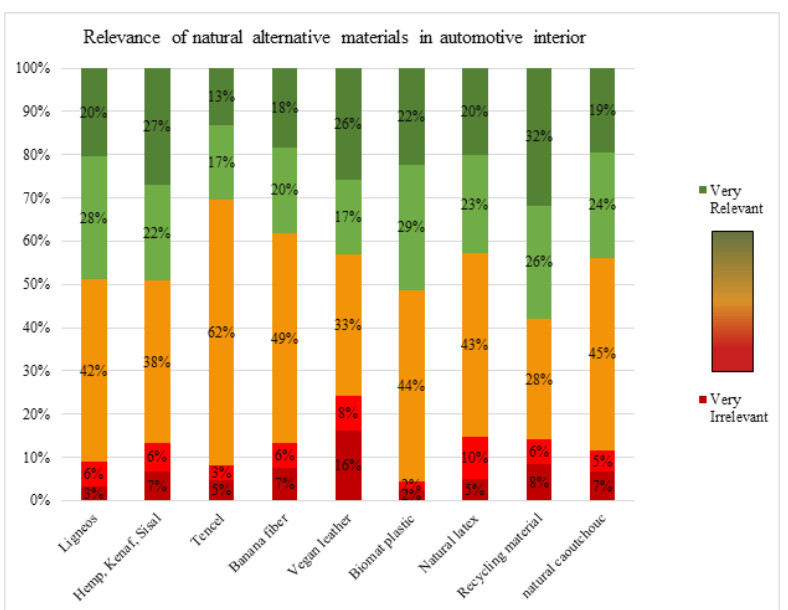

Fig. 7. Relevance of natural alternative materials in automotive interior $(n=254)$

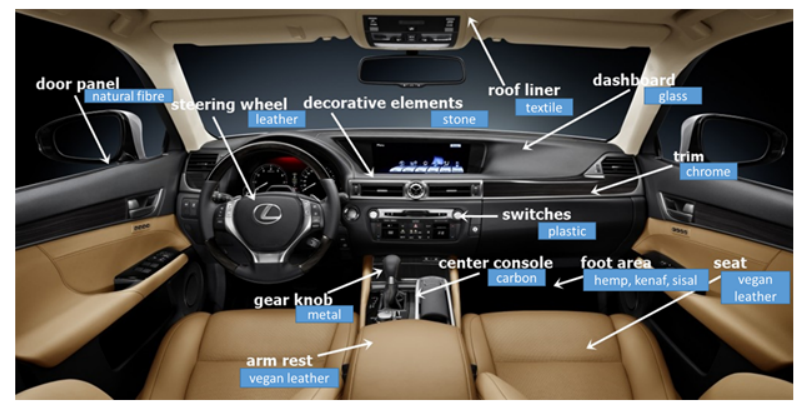

Fig. 8. Interior components with corresponding materials ( $n$ = 177)

The question whether natural materials should be more noticeable in interior design compared to conventional materials produces mixed response. 35 percent of all participants highlight that natural materials should be noticeable, whereas 26 percent disagree with this statement (see Figure 9). The majority of customers are neutral regarding this question.

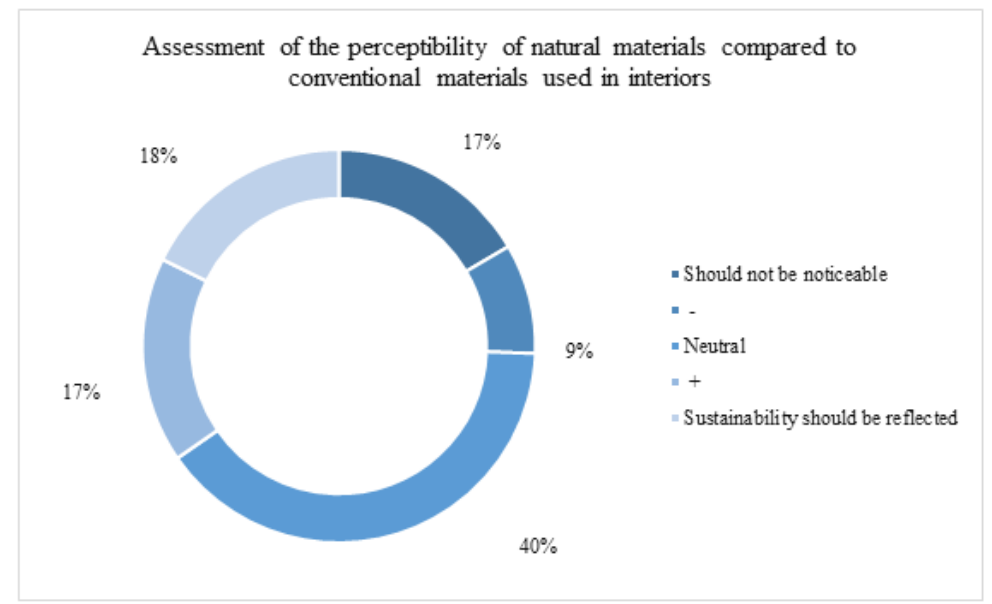

Fig. 9. Assessment of the perceptibility of natural materials in the interior $(n=254)$ 
The final topic of the survey is the future relevance of sustainable materials in the interior. Nearly 74 percent of the respondents rate the future relevance as very high or at least high, thus prophesizing an increase in meaning and relevance in the coming years (see Figure 10).

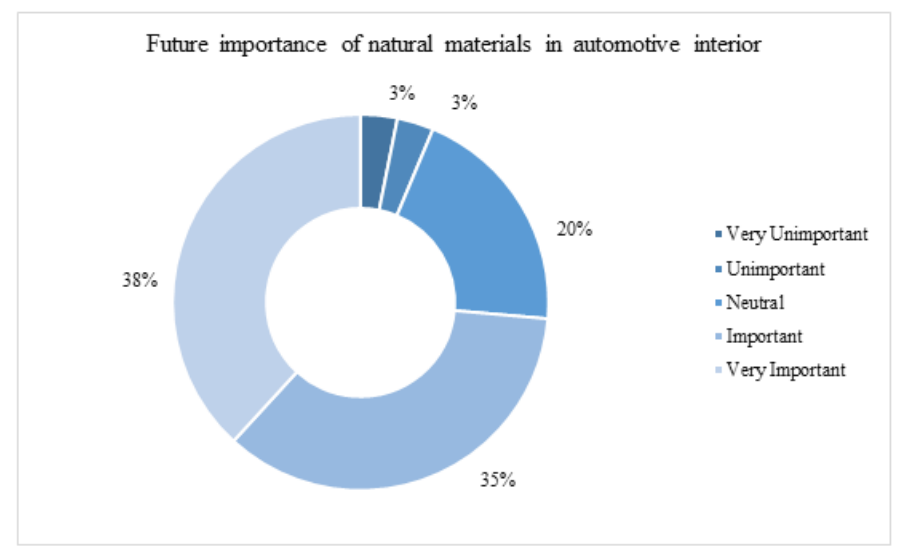

Fig. 10. Future importance of natural materials in automotive interior $(n=254)$

Overall, it can be seen that the issue of sustainability is present in people's awareness. A tendency towards greater openness for new, more sustainable materials among customers of volume brand automobiles is recognizable. The priority for customers is that sustainability is taken into account in manufacturing and production, but not to the detriment of appearance, feel, comfort or price.

\section{DISCUSSION OF THE RESULTS}

There is an agreement in business practice that sustainability is one of the main key success factors. This can be confirmed largely by the empirical results. A majority of 63 percent of all volume brand customers are willing to pay a higher price for additional costs related to the use of natural and sustainable materials. All participants principally agree that sustainability should play an overall role in the automobile and should not be restricted to individual areas. Interior together with electronics even achieve the highest relevance with $70 \%$ percent, followed by powertrain with 66 percent. On The other hand, customers highlight that all traditional criteria connected to automobiles - especially appearance, haptics, comfort, smell, quality, safety and value must be fulfilled at the same time in a sustainable interior. At this point, a problem occurs for manufacturers. Natural materials fulfil certain properties, but others sometimes not. Consequently, manufacturers need to look more closely at this issue in order to satisfy the wishes of their customers. As seen in the empirical study, the majority of participants can imagine a door panel made of natural fibres and some natural materials are already the preferred materials for a few interior parts. The majority of customers also see an increase in the importance of sustainability for the interior on the horizon. It is therefore crucial for manufacturers to be innovative, show initiative, take advantage of emerging market opportunities and to act proactively. The focus should be on achieving first mover advantages, and it is crucial for OEMs to maintain their position as technology leaders. Therefore, it is imperative that volume brand manufacturers concentrate on existing mega-trends - in particular sustainability $[23,28,27]$.

\section{CONCLUSION AND RECOMMENDATIONS}

The automotive industry is a prime example of small steps bringing change and contributing to a more environmentally friendly world. Suppliers are working with manufacturers to find solutions for a more sustainable interior and the importance of implementing sustainability along the entire supply chain is well known to those involved. As a result, technological progress and the refinement of processes for the development of natural fibre products make it possible to replace products that currently pollute the environment more simply and cost-effectively with more environmentally friendly products, and at the same time to produce them in a more environmentally friendly way $[16,17]$. This article focuses exclusively on volume brand manufacturers and their customers. Further research projects will analyse whether there are significant differences when it comes to premium manufacturers. Furthermore, no distinction has been made between age, gender and automotive brand. All of these can be explored in the scope of further research activities, too. 


\section{REFERENCES}

[1] J. D. Mittelstaedt, C. J. Shultz, W. E. Kilbourne, and M. Peterson, "Sustainability as megatrend: Two schools of macromarketing thought," Journal of Macromarketing, vol. 34, no. 3, pp. 253-264, 2014. doi: https://doi.org/10.1177/ 0276146713520551

[2] P. Treshani and K. G. A. S. Waidyasekara, "Sustainable responses to minimise recessionary effects in the Sri Lankan construction industry," International Journal of Technology and Engineering Studies, vol. 1, no. 3, pp. 87-97, 2015. doi: https://doi.org/10.20469/ijtes.40004-3

[3] J. H. Thun and D. Hoenig, "An empirical analysis of supply chain risk management in the German automotive industry," International Journal of Production Economics, vol. 131, no. 1, pp. 242-249, 2011. doi: https://doi.org/10.1016/j.ijpe. 2009.10.010

[4] H. Wallentowitz and J. Leyers, Technology Trends in Vehicle Technology Dimensions, Processes and Interactions. Berlin, Heidelberg: Springer Gabler, 2014.

[5] G. Schuh, C. Kelzenberg, J. Wiese, and F. . Stracke, "Industry 4.0 implementation framework for the producing industry," Journal of Advances in Technology and Engineering Studies, vol. 4, no. 2, pp. 79-90, 2018. doi: https://doi.org/10.20474/ jater-4.2.4

[6] S. Pischinger and U. Seiffert, Ausblick Wo Gehtes Hin. In S. Pischinger and U. Seiffert (Eds.), Vieweg handbuch kraftfahrzeugtechnik. Springer, 2016.

[7] S. Aneeka and Z. W. Zhong, "NOX and $\mathrm{CO}_{2}$ emissions from current air traffic in ASEAN region and benefits of free route airspace implementation," Journal of Applied and Physical Sciences, vol. 2, no. 2, pp. 32-36, 2016. doi: https: //doi.org/10.20474/japs-2.2.1

[8] J. Dannenberg, “Auf einkaufstour," Automobil Industrie, vol. 62, no. 6, pp. 8-12, 2017. doi: https://doi.org/10.1055/ s-0036-1575539

[9] M. Koers, Industrie und Politik Zusammenspiel als Basis profitablen Wachstums in der Automobilindustrie. In B. Ebel and M. B. Hofer (Eds.), Automotive Management Strategic und Marketing in der Automobilwirtschaft. Berlin, Germany: Springer, 2014.

[10] B. Nunes and D. Bennett, "Green operations initiatives in the automotive industry: An environmental reports analysis and benchmarking study," Benchmarking: An International Journal, vol. 17, no. 3, pp. 396-420, 2010. doi: https://doi. org/10.1108/14635771080001423

[11] S. G. Azevedo, H. Carvalho, S. Duarte, and V. Cruz-Machado, “Influence of green and lean upstream supply chain management practices on business sustainability," IEEE Transactions on Engineering Management, vol. 59, no. 4, pp. 753-765, 2012. doi: https://doi.org/10.1109/tem.2012.2189108

[12] W. Jeong, M. Kim, J. Park, and J. H. Roh, "Relation between air pollutants emissions and BESS capacity operated for maximizing customer's profit," Journal of Applied and Physical Sciences, vol. 2, no. 2, pp. 54-64, 2016. doi: https://doi. org/10.20474/japs-2.2.5

[13] S. G. Azevedo and M. Barros, "The application of the triple bottom line approach to sustainability assessment: The case study of the UK automotive supply chain." Journal of Industrial Engineering and Management, vol. 10, no. 2, pp. 286-322, 2017. doi: https://doi.org/10.3926/jiem.1996

[14] P. Sinha, S. S. Muthu, I. Taylor, R. Schulze, K. Beverley, C. Day, and N. Tipi, “'Systems thinking in designing automotive textile," Textiles and Clothing Sustainability, vol. 1, no. 1, pp. 6-12,2015. doi: https://doi.org/10.1186/s40689-015-0004-z

[15] N. Kumar and D. Das, "Fibrous biocomposites from nettle (girardinia diversifolia) and poly (lactic acid) fibers for automotive dashboard panel application," Composites Part B: Engineering, vol. 130, no. 6, pp. 54-63, 2017. doi: https: //doi.org/10.1016/j.compositesb.2017.07.059

[16] R. Dunne, D. Desai, R. Sadiku, and J. Jayaramudu, “A review of natural fibres, their sustainability and automotive applications," Journal of Reinforced Plastics and Composites, vol. 35, no. 13, pp. 1041-1050, 2016. doi: https://doi.org/10. $1177 / 0731684416633898$

[17] J. Hetterich, S. Bonnemeier, M. Pritzke, and A. Georgiadis, "Ecological sustainability a customer requirement? Evidence from the automotive industry," Journal of Environmental Planning and Management, vol. 55, no. 9, pp. 1111-1133, 2012. doi: https://doi.org/10.1080/09640568.2011.636578

[18] S. Pischinger and U. Seiffert, Vieweg Handbuch Kraftfahrzeugtechnik. New York, NY: Springer, 2016. 
[19] J. E. Dölle, Lieferantenmanagement in der Automobilindustrie: Struktur und Entwicklung der Lieferantenbeziehungen von Automobilherstellern. Wiesbaden, Germany: Springer-Verlag, 2013.

[20] T. L. Sullins, "Biocomposite material evaluation and processing for automotive interior components," Ph.D. dissertation, University of Alabama, Tuscaloosa, AL, 2013.

[21] A. Bjurenstedt and F. Lärneklint, 3D Biocomposites for Automotive Interior Parts. New York, NY: John and Willy Son's, 2004.

[22] T. Broker and D. Ostner, "Innere leichtigkeit," Automobil Industrie, vol. 62, no. 8, pp. 94-99, 2017.

[23] S. Gelowicz, T. Gunnel, H. Hammer, and C. Otto, "Mehr als werkstoffe," Automobil Industrie, vol. 62, no. 5, pp. 34-37, 2017.

[24] I. Schmiedel, G. S. Barfuss, T. Nickel, and L. Pfeufer, "Einsatz sichtbarer naturfasern im fahrzeuginterieur," ATZAutomobiltechnische Zeitschrift, vol. 116, no. 6, pp. 34-37, 2014. doi: https://doi.org/10.1007/s35148-014-0424-0

[25] Focus, "Naturliche sache," 2012. [Online]. Available: https://urlzs.com/JR3V

[26] Yanfeng, "Naturfasertechnologie von yanfeng automotive interiors trifft den zeitgeist," 2017. [Online]. Available: https://urlzs.com/95zt

[27] D. Scale Guest, Relationship between Customer Satisfaction and Customer Loyalty ant: An Empirical Analysis using the example of the German Automotive Industry. Berlin, Germany: Springer-Verlag, 2012.

[28] W. Schade, C. Zanker, A. Kuhn, and T. Hettesheimer, Sieben Herausforderungen fur die Deutsche Automobilindustrie: Strategische Antworten im Spannungsfeld von Globalisierung, Produkt-und Dienstleistungs Innovationen Bis 2030. California, CA: Sigma, 2014. 